\section{Old age psychiatry ${ }^{\dagger}$}

\author{
ALISTAIR BURNS and IAN G. MCKEITH
}

It is both fashionable and necessary these days to start any presentation by declaring one's conflicts of interest. As editors of this special supplement we therefore declare our interest in old age psychiatry. Not so long ago cynically described as a Cinderella speciality, old age psychiatry has in the past few years become an increasingly popular clinical career choice. Community-oriented, multi-disciplinary services that remain relatively unfettered by excessive bureaucracy would of themselves be an attractive option in a largely demoralised health care system - but there are other reasons that the speciality is thriving. Not least are the enormous advances that have been made over the past decade in our understanding of the neurobiological basis of late-life psychiatric disorders. Dementia, in particular, has attracted the attention of toplevel neuroscientists who have applied a combination of classical neuropathology, molecular genetics and protein chemistry to reveal some of the key events underlying neurodegeneration. As a result it is conceivable that effective treatments to delay or prevent the onset of Alzheimer's disease could be available within a decade - something that was virtually unthinkable only 10 years ago. Old age psychiatry clinicians are near enough to this buzz to feel it and be excited by it. The differential diagnosis of dementia subtype is now an important part of assessment, the convergence of clinical descriptions of Lewy body dementia and frontotemporal dementia (to give but two examples covered in this issue) allowing increased sophistication in terms of diagnostic reporting by clinicians. These distinctions can lead directly to important management decisions, such as the avoidance of neuroleptic agents in Lewy body disease or the use of cholinesterase inhibitors in Alzheimer's disease. Recognition that disorders hitherto regarded as

†See pp. 116-167, this issue. functional in nature have an organic basis has stimulated research into uncovering aetiological factors and has again influenced clinical practice. Furthermore, improved methods of measuring symptoms in valid and reliable ways have enabled the effects of therapeutic interventions, especially drug trials, to be assessed in ways that are sufficiently robust to allow regulatory authorities to be convinced of their worth.

Our reason for presenting this series of invited papers on the subject of old age psychiatry is to inform the general reader about the major issues, challenges and successes in the speciality today. The following contributions are not intended to be a comprehensive survey of an increasingly widening field, but have been chosen to give a flavour of the richness of clinical practice and research. We have chosen to concentrate on descriptions of organically based syndromes, their differential diagnosis and their effects.

\section{CURRENT RESEARCH}

Holmes (2002, this issue) has summarised much of the current information concerning molecular biology and Alzheimer's disease, emphasising the importance that genes can have as risk factors for the disease and stepping outside the often narrow way of thinking which tends to tunnel our vision into equating the genetics of this disease with those early-onset and rare mutations. This is clearly a field where there is much promise in terms of treatment. This is a theme continued by Bullock (2002, this issue) in his summary of new drugs for Alzheimer's disease. We now have three anticholinesterase drugs available for the treatment of mild to moderate Alzheimer's disease that have been approved by the National Institute for Clinical Excellence in the UK. The role of these drugs in the treatment of Alzheimer's disease will become apparent with continued clinical practice influenced by an appropriate audit of their use and benefit to patients. Snowden et al (2002, this issue) provide an up-to-date summary of frontotemporal dementia, drawing together the clinical, neuropsychological and pathological expertise of the group, who were instrumental in the clinical descriptions of what is a relatively common, but underrecognised, cause of dementia, particularly in younger people. Vascular dementia, which in most samples pips frontotemporal dementia to the post as one of the more common causes of the syndrome, is summarised by Stewart (2002, this issue) and the lack of clear blue water between Alzheimer's disease and vascular dementia is plainly acknowledged - a problem that is increasingly influencing clinical practice as well as taxing epidemiologists. The theme of vascular disease is continued with the review of the vascular basis of depression by Baldwin \& O’Brien (2002, this issue). This condition may explain some elements of treatment resistance in practice and also has implications for the management of patients. Subcortical dementia is summarised by Turner et al (2002, this issue), who emphasise the phenomenological aspects of dementia that have aetiological importance. Jacoby (2002, this issue) brings to the fore many of the legal aspects of old age psychiatry which are increasingly becoming part of everyday clinical practice, particularly in relation to consent, euthanasia and mental capacity. The interface between health and social care is highlighted by Challis \& Hughes (2002, this issue), and the current political climate is such that this distinction - while clinically blurred in many situations - is becoming more important in administrative and financial terms. Costs of care are an essential underpinning of considerations of clinical care, and Kavanagh \& Knapp (2002, this issue) describe some of the models underlying many of the assumptions made by those predicting the cost of caring for people with cognitive impairment. Our own contributions concern dementia with Lewy bodies (McKeith, 2002, this issue) and the use of rating scales in old age psychiatry (Burns et al, 2002, this issue).

\section{THE FUTURE}

We hope that there is useful new information here for those practising old age psychiatry. Two of the costs of being in a 
rapidly changing and expanding field are those of keeping abreast of the new information and of meeting rising public expectations of what can, should and might be done. It is not uncommon now for patients to present themselves to one of the burgeoning number of memory clinics in the UK, asking for early diagnosis and treatment and well aware of recent guidance from the National Institute for Clinical Excellence that the new antidementia drugs should be made available to them within the National Health Service, and the recently published National Service Framework for Older People sets out specific standards of care and aspirations for good practice across a wide range of mental health care issues. So, challenges we have in plenty. This collection of papers gives some indication of how we are responding.

\section{DECLARATION OF INTEREST}

None.

ALISTAIR BURNS, FRCPsych, University of Manchester, Withington Hospital, Manchester; IAN G. McKEITH, FRCPsych, Newcastle General Hospital, Newcastle upon Tyne, UK

Correspondence: Professor Alistair Burns, Department of Psychiatry, Education and Research Centre, Wythenshawe Hospital, Southmoor Road, Manchester M23 9LT, UK. Tel: +44 (0)161 291 3310;

Fax: +44 (0)16I 291 5862; e-mail: a_burns@fsl.with.man.ac.uk

(First received I August 200I, final revision 9 August 200I, accepted I0 August 200I)

\section{REFERENCES}

Baldwin, R. C. \& O'Brien, J. (2002) Vascular basis of late-onset depressive disorder. British Journal of Psychiatry, 180, 157-160.

Bullock, R. (2002) New drugs for Alzheimer's disease and other dementias. British Journal of Psychiatry, $\mathbf{1 8 0}$, 135-139.

Burns, A., Lawlor, B. \& Craig, S. (2002) Rating scales in old age psychiatry. British Journal of Psychiatry, $\mathbf{1 8 0}$, $161-167$.

Challis, D. \& Hughes, J. (2002) Frail old people at the margins of care: some recent research findings. British Journal of Psychiatry, 180, 126-130.

Department of Health (2002) National Service Framework for Older People. London: Department of Health.

Holmes, C. (2002) Genotype and phenotype in Alzheimer's disease. British Journal of Psychiatry, 180 $13 \mid-134$.
Jacoby, R. (2002) Old age psychiatry and the law. British Journal of Psychiatry, 180, 116-119.

Kavanagh, S. \& Knapp, M. (2002) Costs and cognitive disability: modelling the underlying associations. British Journal of Psychiatry, 180, 120-125.

McKeith, I. G. (2002) Dementia with Lewy bodies. British Journal of Psychiatry, 180, 144-147.

Snowden, J. S., Neary, D. \& Mann, D. M. A. (2002) Frontotemporal dementia. British Journal of Psychiatry, 180, 140-143.

Stewart, R. (2002) Vascular dementia: a diagnosis running out of time. British Journal of Psychiatry, $\mathbf{1 8 0}$ 152-156.

Turner, M. A., Moran, N. F. \& Kopelman, M. D. (2002) Subcortical dementia. British Journal of Psychiatry, 180, |48-|5|. 